\title{
POLÍTICAS DA UNIÃO EUROPEIA: INTERESSES E IMPLICAÇÕES PARA A COMERCIALIZAÇÃO DE BIOCOMBUSTÍVEIS BRASILEIROS
}

\author{
Tamara Silvana Menuzzi Diverio \\ Universidade de Cruz Alta (UNICRUZ), Cruz Alta, RS, Brasil \\ tdiverio@unicruz.edu.br
}

Rui Manuel de Sousa Fragoso Universidade de Évora, Évora, Portugal rfragoso@uevora.pt

Luiz Gustavo Zuliani da Silva

Universidade Regional Integrada do Alto Uruguai e das Missões (URI), Frederico Westphalen, RS, Brasil zuliani@uri.edu.br

Recebido em: 07/07/2015; Aceito para publicação em: 23/05/2016

\section{RESUMO}

Este estudo buscou compreender as políticas de biocombustíveis adotadas pela União Europeia (UE) e Brasil, interesses e posições divergentes que se formam em torno das negociações comerciais de biocombustíveis. As reflexões sobre o assunto foram amparadas na teoria dos jogos de dois níveis, na qual parte-se do pressuposto de que toda negociação internacional envolve uma dimensão doméstica. Os resultados encontrados evidenciaram interesses heterogêneos e visões diferenciadas envolvendo a política para biocombustíveis na UE e Brasil. Foram percebidos, assim, dois modelos em disputa que representam públicos e visões diferenciadas. Com o aumento do interesse por política internacional, em virtude, principalmente, do aumento da internacionalização, muitos atores saíram em defesa de seus interesses, o que acentuou as divergências de posições nas discussões das políticas de biocombustíveis.

Palavras-chave: Negociação internacional; Grupos de Interesse; Jogos de dois Níveis.

\section{EUROPEAN UNION POLICIES: INTERESTS AND IMPLICATIONS FOR COMMERCIALIZATION OF BIOFUELS BRAZILIAN}

\begin{abstract}
This study sought to understand the biofuel policies adopted by the European Union (EU) and Brazil, interests and divergent positions that form around the trade negotiations of biofuels. The reflections on the subject were supported in the theory of two-level games, in which assumes that all international trade involves a domestic dimension. The results showed heterogeneous interests and different views involving policy for biofuels in the EU and Brazil. They were perceived thus two models in dispute representing public and different views. With the increase of the interest for international politics, due, mainly, to the increase of the internationalization, many actors came to the defense of their interests, what accented the divergences of position in the arguments of biofuel policies.
\end{abstract}

Keywords: International Negotiation; Interest Groups; Levels two Games.

$\begin{array}{lllll}\text { Caminhos de Geografia } & \text { Uberlândia } & \text { v. 17, n. } 58 \quad \text { Junho/2016 } & \text { p. 103-116 } & \text { Página } 1\end{array}$




\section{INTRODUÇÃO}

Desde a metade da década de 1990 vem se ampliando o olhar sobre os papéis desempenhados pelas famílias rurais, "para além da produção", e com isso vem se consolidando, cada vez mais, o debate público e das políticas agrícolas, ambientais e rurais no aspecto das preocupações não comerciais. Tem ocorrido, ainda que de maneira incipiente, a valorização dos múltiplos papéis desempenhados pela agricultura, principalmente a de base familiar, verifica-se, do mesmo modo, que as políticas públicas têm andado na direção da "territorialização" das suas ações. Conectada a esses temas está a constatação dos atores envolvidos ou eliminados do processo e das percepções sobre os papéis da agricultura no desenvolvimento rural.

As discussões sobre os múltiplos papéis da agricultura geram discussões nacionais e internacionais que expressam preocupações com questões de equidade social e sustentabilidade ambiental, ao mesmo tempo em que são portadoras de "novos" temas ou novos olhares sobre a atividade agrícola e o mundo rural, além de gerarem certa tensão entre a retórica "não produtivista", que se tem multiplicado em várias partes do mundo, em tensão com o linguajar hegemônico do agronegócio.

No que se refere especificamente, às transações agrícolas internacionais, acredita-se que as negociações da Organização Mundial do Comércio (OMC) comprometem os setores agrícolas da economia, tanto europeus como brasileiro de formas diferentes, o que leva determinados setores a terem reações mais ofensivas e outros a serem mais defensivos. Enquanto alguns atores apresentam um discurso em que destacam a liberalização do comércio agrícola como diretriz a ser seguida; outros adotam uma postura mais de proteção ao mercado e, especialmente, inserem na discussão temas como soberania, segurança alimentar e sustentabilidade.

Desse modo, os embates, principalmente entre os dois modelos, o liberal e o mais protecionista, acabam impedindo uma formulação de estratégias conjuntas para 0 desenvolvimento geral da agricultura mundial, comprometendo, de certa forma, o processo de desenvolvimento de uma maneira geral.

Nas negociações agrícolas internacionais existem dois modelos ativos: de um lado, o liberalismo ativo, que implica desproteção ou regulamentação mínima, e, por outro, a proteção ativa, que implica proteger interesses, sejam eles no Brasil, na Europa, nos EUA ou qualquer outro país. Nesse sentido, cada país tem os seus governantes que procuram utilizar os instrumentos de política econômica e financeira para ampliar as vantagens dos seus atores econômicos. No primeiro caso, o do liberalismo ativo, significa até incentivar aqueles que bem se inserem no processo de globalização empresarial e financeira, a hegemônica, domínio das maiores produções e exportações. No segundo caso, o de maior proteção, significa ter uma posição mais defensiva, apoiando com políticas públicas, pequenos produtores e outros atores que, no conjunto, permitem um meio rural vivo e com sustentabilidade, com aquela base multidimensional - econômica ecológica/ambiental e social/cultural. $\mathrm{Na}$ Europa, o segundo caso insere-se numa parte fundamental da Política Agrícola Comum da União Europeia (PAC), e, no Brasil, também, já ganha algum peso e bastante compreensão sobre a sua razão de ser.

Assim, o exame das limitações existentes para a articulação de políticas, instituições e a construção de estratégias de desenvolvimento, principalmente no meio rural, deve levar em consideração os programas e políticas existentes.

Neste caso, buscam-se compreender as políticas de biocombustíveis adotadas pela UE e Brasil, interesses, posições e divergências que se formam em torno das negociações comerciais de biocombustíveis. Para o estudo, utilizar-se-á a obra "Diplomacy and Domestic Politics: The Logic of Two-level Games", de 1988, de Robert Putnam. No trabalho desse autor há o pressuposto de que toda negociação internacional envolve uma dimensão doméstica. Esta dimensão, do ponto de vista conceitual, resulta em uma coalizão vencedora que se articula no plano doméstico, que estabelece os limites para o negociador do país atuar no contexto internacional com os demais negociadores que representam seus respectivos países.

A relevância da pesquisa reside no avanço das discussões sobre a liberalização do comércio, lembrando que esse tema envolve a própria sobrevivência econômica e o desenvolvimento de

$\begin{array}{lllll}\text { Caminhos de Geografia } & \text { Uberlândia } & \text { v. 17, n. } 58 \quad \text { Junho/2016 } & \text { p. 103-116 } & \text { Página } 2\end{array}$


cada país, em especial, o Brasil, refletindo diretamente na geração de emprego e renda de grande parte dos agricultores. Salienta-se que pesquisas deste tipo, tanto contribuem para ampliar o conhecimento sobre o protecionismo e o liberalismo na área de negociações agrícolas internacionais, como mostram que decisões tomadas em nível internacional podem ter consequências perversas para o desenvolvimento dos países.

\section{APORTE TEÓRICO: JOGOS DE DOIS NÍVEIS}

No intuito de desenvolver este estudo foi utilizado o instrumento oferecido pela abordagem teórica dos Jogos de Dois Níveis - cujo principal expoente é Robert Putnam (1988). O autor começa a discutir a relação entre o doméstico e o internacional no fim dos anos 80 , com seu trabalho intitulado Diplomacy and Domestic Politics: The Logic of Two-Level Games. Este estudo dá o passo inicial para outras pesquisas voltadas para a integração das arenas interna e externa em processos de negociação internacional. Para Putnam (2010), a política doméstica e as relações internacionais estão vinculadas. Essa vinculação é resultado da aproximação, relativamente recente e sistemática, das consequências da democracia sobre relações entre assuntos domésticos e internacionais na política externa.

O autor afirma que uma concepção mais adequada dos determinantes domésticos da política externa e das relações internacionais deve enfatizar as lutas políticas. Para Putnam (2010), os poderes executivos têm função principal nas mediações das pressões internacionais e domésticas pelo fato de estarem diretamente expostas a ambas as esferas. Desse modo, o líder que não consegue satisfazer seu ambiente doméstico arrisca-se a ser privado de seu posto.

Utilizando a metáfora dos "Jogos de dois níveis", o autor analisa o fracasso dos acordos internacionais. De acordo com essa teoria, o governo é pressionado pela necessidade de atender demandas domésticas e, assim, obter apoio às suas decisões. Para Putnam (1988), a cooperação internacional pode avançar ou se limitar conforme o poder de veto, ou o apoio de atores internos às decisões a respeito dos acordos internacionais.

O referido autor acredita ainda que movimentos no plano internacional são capazes de intervir no ambiente doméstico do ator negociador e de flexibilizá-lo, aumentando assim as possibilidades de que os oponentes possam tirar dele concessões mais expressivas. Conforme esclarece Putnam (1988), em negociações internacionais, mais especificamente no plano externo, há países que lutam para obter mais vantagens comerciais para si. Já no plano interno, existem grupos de interesse que pressionam o governo para que este adote medidas que os favoreçam. Desse modo, para a Teoria dos Jogos de dois Níveis, os chefes de governo estão posicionados estrategicamente entre "dois tabuleiros": um formado pela política doméstica, e outro, pelas negociações internacionais.

\section{POSIÇÃO PROTECIONISTA NAS NEGOCIAÇÕES COMERCIAIS PARA BIOCOMBUSTÍVEIS}

Em meio às políticas da UE, sobressaem-se as que procuram abordar o mercado dos biocombustíveis, e nesta conjuntura, orientar, normalizar, regular a produção e a incorporação de biocombustíveis no consumo energético, seja de biodiesel e do bioetanol. Sendo assim, na metade dos anos 1990, as energias derivadas de fontes renováveis, abrangendo os biocombustíveis são enfrentadas com maior importância e compromisso pela UE, que adota um conjunto de políticas energéticas voltadas para os biocombustíveis. A exploração das fontes de energias renováveis na UE é muito escassa, podendo estas adotar a tríplice função: (a) diminuir a vinculação de importações de energia e aumentar a segurança do abastecimento; (b) reduzir o impacto ambiental do emprego de energias convencionais; e (c) aumentar as possibilidades de negócio para as empresas europeias (FREITAS e QUEIRÓS, 2012).

Cabe salientar que a defesa da multifuncionalidade tornou-se um ponto importante para a Comunidade Econômica Europeia (CEE) nas negociações internacionais e no processo preparatório da rodada de negociações na OMC, a Rodada de Doha. Posteriormente, ao

$\begin{array}{lllll}\text { Caminhos de Geografia } & \text { Uberlândia } & \text { v. 17, n. } 58 \quad \text { Junho/2016 } & \text { p. 103-116 } & \text { Página } 3\end{array}$


lançamento da Rodada de Doha, as preocupações não comerciais permaneceram um dos pontos importantes do discurso da CEE (MESQUITA, 2005).

A utilização de biocombustíveis pela UE está inserida no âmbito de estratégias para redução dos Gases do Efeito Estufa (GEE) derivada dos compromissos assumidos no Protocolo de Quioto. Os Decretos-lei têm como objetivo a colocação de biocombustíveis renováveis no mercado em substituição aos combustíveis fósseis, principalmente para o setor dos transportes (MALHÃO, 2009).

Embora a existência de algumas experiências nacionais sobre a utilização de biocombustíveis, o amplo impulso aos biocombustíveis nos países europeus deriva do estímulo do Parlamento e do Conselho Europeu para a adoção desta alternativa energética para combater a aumento da emissão de gases geradores do efeito estufa e diminuir a dependência do petróleo no setor de transportes (FIGUEIRA, 2005).

Cabe lembrar que a política Europeia para biocombustíveis é delineada através de diretivas. A diretiva distingue-se dos regulamentos, os quais são executáveis como leis e não necessitam de quaisquer medidas de execução. As diretivas, ao contrário, necessitam ser transpostas para a legislação nacional e deixam os Estados com certa margem de manobra quanto às regras a serem adotadas (DI BARTOLO, 2012).

As diretivas da promoção de energias renováveis da UE definem uma meta obrigatória e transversal para todos os Estados Membros de 10\% de energia renovável nos transportes até 2020. Define ainda critérios de sustentabilidade para os biocombustíveis incorporados na UE e a criação de um mecanismo de certificação (MALHÃO, 2009).

Para expandir o uso de biocombustíveis na UE, os Estados-Membros precisarão garantir que seja colocado nos seus mercados um volume mínimo de biocombustíveis e de outros combustíveis renováveis, e instituem metas sugestivas nacionais para o efeito (FIGUEIRA, 2005). Cabe ressaltar, que todos os países que compõem a UE precisam ajustar suas políticas energéticas nacionais em relação às orientações de política da UE, que se direcionam para as energias renováveis.

No ano de 2003, o Parlamento e o Conselho Europeu aprovaram a Directiva 2003/30/CE (Diretiva Biocombustíveis) para o uso de biocombustíveis no setor de transportes. As pesquisas assinalavam que de 1990 a 2010 o mencionado setor seria responsável pelo acréscimo em $50 \%$ das emissões de $\mathrm{CO}_{2}$, evento que atrapalharia a UE a cumprir as metas no corte de $\mathrm{CO}_{2}$ diante dos acordos assumidos no Protocolo de Quioto. Além disso, o documento mencionado instituiu um conjunto de normas para a adoção dos biocombustíveis (DIRECTIVA 2003/30/CE; FREITAS e QUEIRÓS, 2012).

Esta diretiva para combustíveis da UE de 2003 institui objetivos de mistura para os países membros. Em 2010, os biocombustíveis representavam 4,26\% de todo o consumo de combustível para transporte na UE, e o biodiesel tinha função mais importante do que o bioetanol em termos quantitativos. Essa diretriz europeia estipulou que essa cota precisaria crescer até $5,75 \%$ no final de 2010 , mas a meta não foi alcançada. Até 2020 , pelo menos $10 \%$ da energia empregada no setor de transportes precisará ter origem em fontes renováveis. $O$ biocombustível produzido internamente é pouco para atender à demanda, o que torna a UE importadora de bioetanol e biodiesel (ZILLA e RÖHRKASTEN, 2012).

Ainda neste ano de 2003, surgiu a Directiva 2003/96/CE, com a intenção de reestruturar a anterior no que se refere à taxação dos produtos energéticos e eletricidade. Como os biocombustíveis são mais custosos que os combustíveis convencionais, a Diretiva permite aos Estados-Membros que apliquem parcial ou totalmente a isenção de imposto sobre os biocombustíveis (DIRECTIVA 2003/96/CE).

Os regulamentos contidos nas Diretivas de Biocombustíveis de 2003 forçam que os países membros averiguem se os novos tipos de combustíveis, como o bioetanol e o biodiesel, respeitam as normas técnicas, se a produção dos biocombustíveis não está acontecendo em terrenos de alta biodiversidade e se as matérias-primas não afetam a produção de alimentos. Também o documento estimula o desenvolvimento tecnológico dos biocombustíveis de segunda geração. Assim, os países membros da UE têm, cada qual, obrigações para

$\begin{array}{lllll}\text { Caminhos de Geografia } \quad \text { Uberlândia } & \text { v. 17, n. 58 Junho/2016 } & \text { p. 103-116 Página } 4\end{array}$


desenvolver suas próprias estratégias de como irão introduzir a curto, a médio e a longo prazo os biocombustíveis no setor de transporte. Este documento deixa claro que a promoção da produção e do uso de biocombustíveis poderá contribuir para uma redução da dependência das importações de energia e das emissões de gases com efeito de estufa (FREITAS e QUEIRÓS, 2012).

Em 2005, levando em consideração os preços elevados do petróleo e a urgência de uma nova abordagem para a segurança energética, a Comissão apresentou o Plano de Ação da Biomassa, determinando um acréscimo no desenvolvimento energético através da madeira, resíduos e restos de culturas agrícolas (CARREZ, 2007).

No ano 2006, foi divulgada a Estratégia da UE no Campo dos Biocombustíveis, que teve um preparativo para a revisão da Diretiva dos Biocombustíveis no final de 2006. O objetivo básico foi gerar a produção e consumo de Biocombustíveis na Europa, de maneira a preparar em grande escala o uso dos biocombustíveis e explorar oportunidades para os países desenvolvidos no que se refere à produção de plantas que produzirão biocombustíveis (CARREZ, 2007).

Em Junho de 2009, a UE lançou a Diretiva de Energia Renovável com metas ambiciosas para todos os estados membros. Esta directiva 2009/28/CE do Parlamento e do Conselho Europeu revoga as Diretivas anteriores e reafirma os compromissos para com o desenvolvimento comunitário da energia proveniente de fontes renováveis para além de 2010. Esta diretiva de 2009 delimita como cada um dos países deve contribuir para atingir a meta geral: $20 \%$ de toda a energia utilizada dentro da UE devem ser oriundos de fontes renováveis até 2020 , sendo que $10 \%$ disso pelo setor de transportes. Incluso à Diretiva, pode-se localizar planos de desenvolvimento para introdução e desenvolvimento de fontes enérgicas renováveis (GLENISTER e NUNES, 2011).

No caso de biocombustíveis, esta diretiva apresenta os critérios de sustentabilidade que específica se um biocombustível deve contar para a meta de energia renovável dos estados membros. Os critérios de sustentabilidade podem ser desmembrados em 12 fatores diferentes: (a) Legalidade; (b) Direitos Humanos e Trabalhistas; (c) Segurança Alimentar Local; (d) Emissões de Gases de Efeito Estufa; (e) Direitos Fundiários; ( $f$ ) Desenvolvimento Rural e Social; (g) Planejamento, Monitoramento e Melhoria Contínua; (h) Conservação; (i) Uso de Tecnologia, Insumos e Gestão de Resíduos; (j) Água; (k) Solo; e (I) Ar. Caso os critérios de sustentabilidade não sejam atendidos, este biocombustível não é considerado como fonte energética renovável sustentável. Ao garantir que os países dentro da UE se vinculem aos critérios de sustentabilidade, a UE busca limitar aqueles que não geram economias líquidas de GEE, que tenham impactos negativos sobre o meio ambiente, biodiversidade ou uso da terra (GLENISTER e NUNES, 2011).

A UE pretende garantir que somente biocombustíveis produzidos de modo sustentável sejam compreendidos na percentagem de mistura. Os biocombustíveis só computam para percentagens de mistura se a emissão de gases do efeito estufa atribuíveis a toda a sua cadeia de produção forem pelo menos $35 \%$ mais baixas do que sua equivalência em combustível fóssil, e a biomassa empregada não pode ser cultivada em terras ecologicamente valiosas.

Cabe salientar que os biocombustíveis são empregados para garantir e diversificar o abastecimento de energia e promover a conquista de metas climáticas, bem como para incitar o desenvolvimento econômico e criar novos postos de trabalho, de maneira especial nas áreas rurais. No entanto, para alcançar as metas de mistura de biocombustíveis, a UE precisará cada vez mais das importações de países em desenvolvimento e países recém-industrializados. No entanto, há um receio de que a produção de biocombustíveis dirigida para a exportação em países em desenvolvimento se desenvolva associada a impactos ecológicos e sociais negativos, sobressaindo o risco de que a produção de biocombustíveis leve ao desmatamento, destruição de ecossistemas e deslocamento das plantações de alimentos. As consequências sociais negativas também são debatidas, entre elas, por exemplo, o deslocamento dos pequenos produtores e a exploração dos trabalhadores das plantações (ZILLA e RÖHRKASTEN, 2012).

$\begin{array}{lllll}\text { Caminhos de Geografia } \quad \text { Uberlândia } \quad \text { v. 17, n. } 58 \quad \text { Junho/2016 } & \text { p. 103-116 Página } 5\end{array}$


Sendo assim, levando em consideração questões de sustentabilidade, a posição europeia nas negociações internacionais de biocombustíveis deve levar em conta, de forma mais favorável, as chamadas considerações não comerciais sobre a agricultura. Ou seja, a UE passa a reivindicar que temas como sustentabilidade sejam discutidos e ponderados no momento de uma negociação. É válido ressaltar que, com a Diretiva, a Europa passará a ser o primeiro mercado a exigir uma Certificação Socioambiental dos biocombustíveis (CAVALCANTE, 2010).

Logo, os critérios de sustentabilidade defendidos pela UE acabam sendo vistos por muitos países, em especial o Brasil, como barreiras não tarifárias ao comércio de biocombustíveis. Cabe lembrar que, no comércio internacional não basta a existência de um excedente exportável que possa ser transportado a custo economicamente viável, os países precisam ficar atentos ao caráter discriminatório que as políticas comerciais podem impingir aos produtos agrícolas. Neste quesito destacam-se as barreiras tarifárias e não tarifárias também conhecidas como barreiras comerciais. Barreira comercial pode ser entendida como qualquer lei, regulamento, política, medida ou prática governamental que imponha restrições ao comércio exterior. As barreiras não tarifárias são restrições à entrada de mercadorias importadas que possuam como fundamento requisitos técnicos, sanitários, ambientais, laborais, restrições quantitativas, políticas de valoração aduaneira com preços mínimos e bandas de preços (LIMA, 2005).

\section{DEFESA DE UMA POSIÇÃO LIBERALIZANTE NAS NEGOCIAÇÕES COMERCIAIS PARA BIOCOMBUSTÍVEIS}

O panorama do Brasil, até a década de 1990, era de um país que possuía uma atitude mais conservadora nas transações e negociações comerciais, aproximando-se dos países protecionistas, ou seja, mantinha a economia fechada para o mundo (MACHADO, 2009). Com relação a esse tema, Mancuso e Oliveira (2006) acrescentam que, nos anos 90, ocorreu uma mudança brusca na maneira como o empresariado operava no Brasil. Os referidos autores afirmam que a causa fundamental dessa alteração foi a inflexão liberal na política de estabilização econômica do país, cuja implementação remonta o início do Governo Fernando Collor de Mello.

Com a abertura comercial, a partir da década de 1990, a atitude brasileira foi mais agressiva, principalmente em agricultura, pois os empresários passaram a ter uma maior noção dos custos e danos com a não participação nos processos de negociações internacionais. Isso induziu alguns empresários a se organizarem e a se prepararem de forma efetiva para tentar influenciar as negociações das quais o Brasil participava. Assim, começou a haver um movimento, por parte de organizações representativas, principalmente do agronegócio, com vistas a influenciar a posição negociadora do Brasil.

Dessa forma, as organizações representantes do agronegócio nacional passaram a exigir, cada vez mais, espaço e poder de influência na elaboração de políticas, além de acompanhar mais de perto as negociações no âmbito do regime multilateral de comércio. Com a abertura da economia para o mercado externo, os produtos que essas organizações representavam aumentaram em importância na obtenção de superávits para a balança comercial brasileira, 0 que acabou justificando as demandas que pediam maior participação nas negociações internacionais visando aumentar a exportação de produtos brasileiros para o mercado externo.

A partir de 2003, no governo de Luiz Inácio Lula da Silva, ocorre uma mudança bastante perceptível no posicionamento externo brasileiro, ou seja, a diplomacia passou a dar mais atenção às questões político-estratégicas que conduziram a um movimento mais proativo no campo comercial e no campo político, ampliando o papel do país na política internacional. Nesse cenário, destacam-se dois elementos importantes: a visão do Brasil como global trader e a busca da diplomacia brasileira de colocar o país como global player. Esses elementos traduziram-se em um comportamento decisivo na busca de mercados e investimentos e na candidatura do país a ocupar um assento permanente no Conselho de Segurança das Nações Unidas (SARAIVA, 2007).

A OMC foi avaliada como a melhor alternativa para os interesses brasileiros nas questões econômicas, já que ofereceria possibilidade de o país se resguardar contra excessos, além de

$\begin{array}{lllll}\text { Caminhos de Geografia } & \text { Uberlândia } & \text { v. 17, n. } 58 \quad \text { Junho/2016 } & \text { p. 103-116 } & \text { Página } 6\end{array}$


Ihe oferecer recursos apropriados para a resolução razoavelmente justa de conflitos que, de outra maneira, seriam decididos pela regra do mais forte. $O$ autor ressalta ainda que a credibilidade e a legitimidade da estratégia brasileira só foram possíveis pela influência mútua, mais democrática, entre policy-makers e sociedade civil nacional e internacional em vários fóruns, principalmente na OMC (OLIVEIRA, 2007).

No que se refere às políticas públicas voltadas para os biocombustíveis, cabe relembrar que o início da produção de biocombustíveis foi uma resposta aos altos preços do petróleo da década de 1970, que ocorreram devido as restrições impostas pela Organização dos Países Exportadores de Petróleo (OPEP). Os altos preços do petróleo incentivaram inovações com substitutos mais baratos ou mais confiáveis, como os biocombustíveis (BANSE et al., 2008).

Em resposta a este cenário mundial surge no Brasil, o Programa Nacional do álcool (PróÁlcool), que visava substituir os combustíveis veiculares derivados de petróleo por álcool. Este programa foi financiado pelo governo a partir de 1975 devido à crise do petróleo em 1973. Enquanto o governo promovia estudos econômicos para a sua produção em grande escala, oferecendo tecnologia e até mesmo subsídios às usinas produtoras de açúcar e álcool, as indústrias automobilísticas instaladas no Brasil naquele periodo adaptavam seus motores para receber o álcool combustível. Cabe recordar que o primeiro carro a álcool foi lançado em 1978, destacando-se no gosto popular dos brasileiros até 1986, sendo que a quase totalidade dos veículos saídos das montadoras brasileiras neste periodo utilizava esse combustível.

A partir do final da década de 1980, a produção de álcool apresentou queda gradual, devido a alta no preço internacional do açúcar, o que desestimulou a fabricação do produto. Além disso, ocorreu a retirada progressiva dos subsídios à produção, promovendo a quase extinção do Pró-Álcool, além dos problemas técnicos nos motores a álcool, incapazes de um bom desempenho principalmente nos períodos frios. Durante a década de 1990, com altas inesperadas no preço do petróleo, o álcool seria misturado à gasolina, numa taxa em torno de vinte por cento, como forma de amenizar o preço da gasolina ao consumidor.

Diante de uma situação nacional antiga e inconstante, justamente causada pelas altas e baixas do petróleo, as grandes montadoras brasileiras aprofundaram-se em pesquisas e, dessa forma, lançaram uma nova tecnologia, os carros dotados de motor bicombustível, que podem rodar com $100 \%$ de etanol ou qualquer outra combinação de etanol e gasolina.

Já, no que se refere às Políticas públicas voltadas para o Biodiesel, o Governo brasileiro lançou em dezembro de 2004 o Programa Nacional de Produção e Uso do Biodiesel. O PNPB é um Programa Interministerial coordenado pela Casa Civil da Presidência da República e composto por 14 Ministérios responsável pela operacionalização encontra-se o Ministério de Minas e Energia, coordenador do Grupo Gestor do PNPB, composto também pelos mesmos Ministérios, mais Agência Nacional do Petróleo, Gás natural e Biocombustíveis (ANP), Petrobras, Embrapa e Banco Nacional de Desenvolvimento Econômico e Social (BNDES). O objetivo do programa é de implementar de modo sustentável, técnica e economicamente a produção e uso do biodiesel, buscando o desenvolvimento regional através da inclusão social com a criação de emprego e renda, assim como a redução da dependência externa de importações de óleo diesel (MDIC, 2006).

Para esses objetivos, o PNPB articulou sistema de regras, incentivos, programas de capacitação técnica e de pesquisa, que garantem rentabilidade para os produtores e participação da agricultura familiar juntamente com o agronegócio como fornecedores de matéria-prima para a produção de biodiesel. Trata-se de um marco regulatório abrangente que cobre aspectos técnicos, sociais e financeiros de toda a cadeia produtiva do biodiesel.

Segundo Garcez e Vianna (2009), os princípios e diretivas do PNPB são: implementação de um programa de desenvolvimento sustentável; promoção da inclusão social; garantia de preços competitivos, qualidade, suprimento e produção de biodiesel de diferentes plantas oleaginosas em regiões diversas. Duas leis foram editadas nesta linha.

A Lei 11.097, de 13 de janeiro de 2005, introduziu o biodiesel na matriz energética brasileira, fixando em 5\% (cinco por cento), em volume, o percentual mínimo obrigatório de adição de biodiesel ao óleo diesel comercializado ao consumidor final, em qualquer parte do território nacional. Esta lei é o marco regulatório da inserção do biodiesel na matriz energética brasileira,

$\begin{array}{lllll}\text { Caminhos de Geografia } & \text { Uberlândia } & \text { v. 17, n. } 58 \quad \text { Junho/2016 } & \text { p. 103-116 } & \text { Página } 7\end{array}$


sendo estabelecidos, além dos atos legais e os percentuais de mistura do biodiesel ao óleo diesel, também o modo de utilização e o regime tributário distinguido por região de plantio, por oleaginosa e por categoria de produção, agronegócio e agricultura familiar (BRASIL, 2005a).

A Lei 11.116, de 18 de maio de 2005, determinou que o biodiesel necessário ao atendimento dos percentuais terá que ser processado, preferencialmente, a partir de matérias-primas produzidas por agricultor familiar, inclusive as resultantes de atividade extrativista (BRASIL, 2005b).

Nestas leis está intrínseca uma visão ambiental, mercadológica e social das políticas voltadas para o biodiesel. A visão ambiental ressalta que o biodiesel é menos poluente quando comparado ao diesel, apresentando menor teor de enxofre, menor teor de monóxido de carbono, além de outras emissões. Segundo a ANP, cada litro da mistura B5 diminui em 3\% a emissão de $\mathrm{CO}_{2}$. A visão social destaca os objetivos de transferência de renda e desenvolvimento regional do programa, a redução da desigualdade regional e a inserção da agricultura familiar na cadeia produtiva, que são previstas de uma forma mais abrangente no aspecto legal, nos incisos II e III, do $\S 2^{\circ}$, artigo $2^{\circ}$, da Lei 11.097/2005. Por sua vez, a visão mercadológica salienta a disponibilidade de oferta de matéria-prima e a capacidade industrial para produção de biodiesel que está presente no inciso I, do $§ 2^{\circ}$, artigo $2^{\circ}$, da Lei 11.097/2005.

Nas três visões pôde-se constatar a presença do governo como indutor do desenvolvimento do PNPB, enquanto criador de políticas públicas de financiamento, como os leilões de biodiesel promovidos pela ANP, financiamento do BNDES, Programa Banco do Brasil de Apoio à Produção e Uso de Biodiesel e ao assegurar a inserção dos agricultores familiares com o Selo Combustível Social (MENDES, 2012).

Assim, o Brasil tornou-se protagonista na negociação e comercialização de biocombustíveis no mercado internacional e está entre os maiores produtores e consumidores de biodiesel do mundo, sendo o segundo maior produtor de etanol, atrás apenas dos Estados Unidos (Safra 2014/2015) e o maior exportador de etanol (UNICA, 2015).

Atualmente, o etanol brasileiro representa a melhor e mais avançada opção para a produção sustentável de biocombustíveis em larga escala no mundo. O País é o candidato natural a liderar a produção economicamente competitiva e a exportação mundial de etanol, pois tem o menor custo de produção e o maior rendimento em litros por hectare, apresenta balanço energético inigualável e domínio tecnológico nas áreas industrial e agrícola, com possibilidade de ampliar a produção (MAPA, 2015).

O Brasil possui um elevado potencial de produção de cana-de-açúcar e unido à Índia e China devem responder por $85 \%$ da produção de etanol nos países em desenvolvimento. Os investimentos na produção de etanol devem continuar a ocorrer e a produção de etanol derivado da cana-de-açúcar deverá expandir-se rapidamente, crescendo quase $6 \%$ ao ano ao longo do período de projeção para atender a demanda tanto nacionais como internacionais. Brasil deverá ser o segundo maior produtor de etanol, com uma quota de $33 \%$ da produção mundial em 2020 (OCDE, 2011).

Entre as características que favorecem a liderança no setor estão: geografia favorável; grande extensão territorial; situa-se em uma região tropical, com altas taxas de luminosidade e temperaturas médias anuais; associada à disponibilidade hídrica e regularidade de chuvas, torna-se o país com maior potencial para produção de energia renovável; Recursos naturais que possibilitam ampliar a produção de insumos energéticos provenientes da biomassa.

O Brasil, em virtude da grande competitividade agrícola, busca uma real e efetiva liberalização da agricultura no comércio mundial, pois depende da eliminação de proteções e subsídios conferidos ao setor para que possa aproveitar a vantagem comparativa que dispõe. Neste sentido, a posição do governo brasileiro é de atuar efetivamente nas negociações e, com isso, promover uma maior liberalização possível na área agrícola, no âmbito multilateral.

O grande objetivo do Brasil, nas rodadas de negociações, é aumentar o acesso das exportações agrícolas que são prejudicadas por barreiras comerciais que, de forma geral, é aplicado pelos países desenvolvidos. Assim, o Brasil tem uma posição mais agressiva, mais

$\begin{array}{lllll}\text { Caminhos de Geografia } & \text { Uberlândia } & \text { v. 17, n. } 58 \quad \text { Junho/2016 } & \text { p. 103-116 } & \text { Página } 8\end{array}$


liberal, pois defende a expansão e a liberalização do comércio ao máximo. Isso porque tem interesses na abertura de mercado, principalmente, com redução de cotas e tarifas.

Jank e Tachinardi (2006) destacam que o Brasil é exportador líquido em quase todos os produtos da agricultura. Esses autores consideram que a agricultura tanto comercial como familiar são ganhadores com a liberalização agrícola mundial, pois o superávit comercial brasileiro é garantido pelo agronegócio.

Por fim, acredita-se que a estratégia internacional adotada pelo Brasil para a condução das negociações agrícolas, no que se refere à defesa da liberalização comercial, não deve inibir a adoção de políticas ativas de desenvolvimento, classificadas como indesejáveis pelo discurso do liberalismo. Para o futuro, o governo brasileiro tem o desafio de conciliar interesses agrícolas divergentes no ambiente doméstico e ainda conseguir acomodar preocupações e promover interesses variados entre dois tipos de agricultura que existem dentro do país: a agricultura patronal e a agricultura familiar.

\section{CONFLITOS E POSIÇÕES DIVERGENTES NA COMERCIALIZAÇÃO DE BIOCOMBUSTÍVEIS ENTRE UE E BRASIL}

As negociações comerciais de biocombustíveis entre Brasil e UE ocorrem com base nas posições divergentes entre os países. O Brasil, de vertente mais liberal, pretende uma maior abertura dos mercados para biocombustíveis e a UE mais protecionista. Essas divergências incluem assuntos como: sustentabilidade e instrumentos de proteção.

A comercialização de biocombustíveis entre Brasil e UE está pautada em divergências e incertezas, um exemplo são os critérios de sustentabilidade inseridos nas diretivas da UE, que em virtude da generalidade do tema e as dificuldades de colocá-los em prática pelo lado brasileiro - em função do cenário brasileiro de internacionalização e a busca pela liberalização comercial - tornam as discussões em torno do conceito de sustentabilidade difíceis de serem conduzidas, gerando, muitas vezes, divergências e incertezas.

O tema da sustentabilidade, discutido na UE e vinculado aos biocombustíveis, poderá se tornar barreira não tarifária com custo elevado à produção brasileira, pois as diretivas europeias impõem uma série de critérios ambientais para a importação não só do biocombustível, mas também de grãos e óleos que servem de matéria-prima para a produção local do biocombustível. Entre as exigências para atendimento dos critérios está a proibição da plantação de grãos em áreas de pastagens com alta biodiversidade e que o biocombustível importado deve ser capaz de reduzir em $35 \%$ as emissões de gases de efeito estufa, responsáveis pelo aquecimento do planeta.

A cana, considerada eficiente, reduz $71 \%$, pelos cálculos da UE, e $90 \%$ pelos cálculos da União da Indústria da Cana-de-Açúcar brasileira (UNICA). Por sua vez, o percentual de redução de emissões do óleo de canola, matéria-prima muito usada e produzida para biocombustíveis na Europa, é de $36 \%$.

Já a soja, pela metodologia europeia, reduz a poluição em $31 \%$, ou seja, o óleo de soja terá dificuldades de atender aos critérios exigidos pela UE. Assim, apesar de o Brasil não exportar biodiesel, as regras da UE afetariam o setor de soja, pois acabam atingindo toda a cadeia produtiva. A razão é que os europeus têm de exigir certificação do grão ou do óleo importado para produzir localmente o biocombustível. Outro aspecto importante a ser considerado é o fato da norma europeia EN 14214/2005 especificar um limite máximo de $120 \mathrm{~g}$ de lodo/100g de amostra, por outro lado na legislação brasileira, de acordo com a resolução ANP no 42 de 2004, o combustível deve ser analisado antes da comercialização, resultando em um Certificado de Qualidade e, periodicamente, ao final de cada trimestre civil, em relação a todas propriedades físicas e químicas, totalizando 26 parâmetros, entre os quais, o índice de iodo, mas que para este não existe um limite máximo estabelecido, devendo apenas ser registrado seu valor. Cabe salientar que tanto a EN 14214/2005 quanto a resolução ANP no 42 de 2004 adotam a norma EN 14111/2003 como procedimento para determinação do índice de iodo.

\begin{tabular}{lllll}
\hline Caminhos de Geografia & Uberlândia & v. 17, n. $58 \quad$ Junho/2016 & p. 103-116 & Página 9
\end{tabular}


Assim, os produtores de soja brasileiros teriam dificuldades em obter a certificação necessária para poder exportar à UE. Ou seja, os requisitos de certificação também podem funcionar como barreiras não tarifárias à comercialização.

Dados de 2013 lançados pela ANP mostram que a soja está sendo preponderante como matéria-prima de biodiesel, representando $74 \%$ da matéria-prima total usada para produzir o biocombustível. No entanto, uma importante diretriz do PNPB brasileiro é a produção de biodiesel por meio de uma diversidade de matérias-primas e este é um primeiro indicador de ameaça à sustentabilidade ambiental do Programa, pois a soja é uma oleaginosa cultivada em grande escala e na monocultura.

O Brasil é o segundo maior produtor mundial de soja atrás apenas dos Estados Unidos. Considerando-se a produção mundial de soja em grãos safra 2012/2013 a produção total foi de 267,60 milhões de toneladas, sendo Estados Unidos, Brasil e Argentina responsáveis por 81\% da produção mundial de soja em grão. O Brasil é responsável por 30\% (USDA, 2014).

Segundo a Companhia Nacional de Abastecimento (CONAB) a produção nacional brasileira de soja em grão para 2012/2013 foi de 81,2 milhões de toneladas, representando um acréscimo $22,8 \%$ em relação à safra anterior. O Estado de Mato Grosso lidera o ranking da produção nacional com um volume de 23,5 milhões de toneladas, seguido do Paraná (15,9 milhões de toneladas) e do Rio Grande do Sul, onde a pesquisa indica uma produção de 12,5 milhões de toneladas. Visto que o Brasil possui uma estrutura de produção, distribuição e esmagamento de grãos já consolidada, a soja torna-se bastante viável economicamente para a produção de biodiesel.

Para Maisonnett (2011) algumas medidas imputadas pelos países demonstram que as barreiras-técnicas continuam sendo grandes aliadas nas restrições ao comércio internacional. O Brasil tem enfrentado com alguma regularidade barreiras-técnicas às suas atividades comerciais, visto que apresenta significativo mercado exportador na área de produtos agrícolas, e estes envolvem questões técnicas, sanitárias e fitossanitárias. Cabe lembrar ainda que para encobrir prováveis ações protecionistas, os países se valem muitas vezes do próprio acordo sobre Barreiras Técnicas ao Comércio (Thecnical Barriers to Trade - TBT), parte integrante do Acordo de Marrakesh.

Esse Acordo excepciona, em algumas condições, o livre comércio, respaldando-se nas hipóteses em que o produto em questão esteja em desacordo com requisitos mínimos de padrões técnicos exigidos pelo país importador. Ainda que seja obrigatório para seus membros, o Acordo TBT não pressupõe explicitamente as normas e os regulamentos que necessitam ser adotados pelos países. Antes, institui princípios gerais e programáticos com o objetivo de guiar os membros na criação de normas e regras específicas que deverão fazer parte de acordos em matéria de padrões técnicos.

$\mathrm{Na}$ medida em que normas técnicas passam a ser observadas em produtos comercializados, quando determinado bem não está de acordo com as especificações pertinentes, sua venda é proibida, não sendo, contudo, considerada uma medida protecionista (BARRAL et al., 2006). As autoras reforçam ainda que produtores de biocombustíveis podem deparar-se com questões, embora não sendo consideradas "barreiras", podem terminar por limitar a exportação de tais produtos por países menos desenvolvidos, em virtude de impedimentos diversos que oneram a produção e reduzem a margem de competitividade. Ou seja, a falta de comprovação das exigências, poderá resultar no impedimento de acesso a mercados internacionais.

\section{CONSIDERAÇÕES FINAIS}

Para Putnam (1988), a posição defendida no nível internacional deve ser coincidente com o interesse nacional que resulta do jogo político doméstico. Somente assim, explica o autor, haverá implementação no nível doméstico das decisões negociadas a nível internacional. A teoria do jogo de dois níveis, de Putnam (1988), permitiu esclarecer o emaranhado da luta política brasileira nas negociações comerciais de exportação de biocombustíveis e, principalmente, permitiu compreender como tanto o Brasil como a UE se posicionam para ter seus interesses representados no nível externo.

$\begin{array}{lllll}\text { Caminhos de Geografia } & \text { Uberlândia } & \text { v. 17, n. } 58 \quad \text { Junho/2016 } & \text { p. 103-116 } & \text { Página } 10\end{array}$


No que tange às posições do Brasil e da UE sobre as discussões Comerciais de biocombustíveis, percebeu-se que as negociações comprometem os setores agrícolas da economia brasileira e europeia de formas diferentes, o que leva a terem reações mais ofensivas e outros a serem mais defensivos. Por exemplo, observou-se que, no Brasil, apresenta-se um discurso em que destaca a liberalização do comércio agrícola como diretriz a ser seguida; por outro lado, a UE adota uma postura mais de proteção ao mercado europeu e, especialmente, insere na discussão temas como sustentabilidade.

Neste sentido, ficaram bastante perceptíveis visões diferenciadas com interesses heterogêneos entre Brasil e UE na área de biocombustíveis. A visão geral do Brasil é de que se deveria ter uma posição agressiva em função do pressuposto da competitividade natural da agricultura brasileira. Por sua vez, a UE acredita que uma maior liberalização, feita de forma indiscriminada, poderia prejudicar a sustentabilidade mundial, ou seja, esse grupo defende uma posição mais protecionista no que se refere à abertura de mercado.

Essa divisão de posições vem gerando divergências de posições entre Brasil e UE na área de biocombustíveis, pois, conforme Putnam (2010), quando as preferências dos grupos são mais heterogêneas, qualquer acordo no nível I (internacional) atinge desigualmente cada um desses grupos envolvidos.

Ao longo da pesquisa, ficou claro que há dois modelos em disputa, com posições políticas diferenciadas. As políticas divergentes sobre alguns temas das negociações sobre biocombustíveis acabam gerando conflitos políticos entre o Brasil e UE nos momentos da negociação em nível internacional. Os embates, principalmente entre dois grupos importantes da agricultura mundial, acabam impedindo uma formulação de estratégias conjuntas para 0 desenvolvimento geral da agricultura, comprometendo, de certa forma, o processo de desenvolvimento de uma maneira geral. Estes dois grupos partem de paradigmas, concepções diferentes sobre agricultura, mundo rural e desenvolvimento, por isso encontram dificuldades de chegar a um acordo, especialmente nas negociações internacionais de biocombustíveis.

\section{AGRADECIMENTOS}

Este trabalho foi realizado com o apoio da Coordenação de Aperfeiçoamento de Pessoal de Nível Superior (CAPES), processo n. 858413-3.

\section{REFERÊNCIAS}

ANP - Agência Nacional do Petróleo. Resolução n. 42, de 24 de novembro de 2004.

Estabelece a especificação de biodiesel. Diário Oficial da União, Brasília, ed. 236, 2004.

BANSE, M.; MEIJL, H.V.; TABEAU, A.; WOLTJER, G. Impact of EU biofuel policies on world agricultural and food markets. In: 107th EAAE Seminar Modelling of Agricultural and Rural Development Policies. Sevilha, Spain, 2008.

BARRAL, W.; BRANCO, L.G.B.; ESTRELA, A.T.G.; FLORES JR, R.G.; LIMA-CAMPOS, A.; MARQUES, C.; MEDEIROS, S.; MOREIRA, G.A.; PINHEIRO, S.M.; VASCONCELOS, R.B.; VILHENA, P. A lei do bioterrorismo norte-americana e sua repercussão sobre o comércio internacional do Brasil. In: CAMPOS, A. de L. (Org.). Ensaios em Comercio Internacional 2. 1 ed. São Paulo: Singular, 2006. v. 1, p. 231-257.

BRASIL. Lei oㅜ 11.097, de 13 de janeiro de 2005. Diário Oficial [da] República Federativa do Brasil. Poder Executivo, Brasília, DF. 2005a.

. Lei oㅜ 11.116, de 18 de maio de 2005. Diário Oficial [da] República Federativa do Brasil. Poder Executivo, Brasília, DF. 2005b.

CARREZ, D. Biofuels in Europe. 2007. Disponível em:

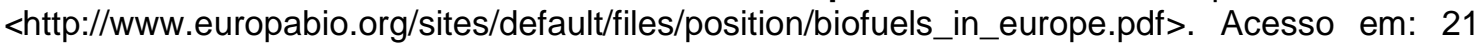
de outubro de 2014.

$\begin{array}{lllll}\text { Caminhos de Geografia } & \text { Uberlândia } & \text { v. 17, n. 58 Junho/2016 } & \text { p. 103-116 } & \text { Página } 11\end{array}$


CAVALCANTE, H.P.M. Aspectos jurídicos relativos ao etanol brasileiro e as barreiras nãotarifárias à sua importação. Direito E-nergia. Ano II, v. 2, p. 1-25, jan./jul. 2010.

DI BARTOLO, T. Avaliação da factibilidade da política de padronização Veicular da União Europeia, a partir da maior inserção do Etanol brasileiro. Dissertação (Mestrado em Planejamento Energético) - Rio de Janeiro: UFRJ. 2012. Disponível em: $<$ http://www.ppe.ufrj.br/ppe/production/tesis/tamara_bartolo.pdf>. Acesso em: 23 de setembro de 2014.

DIRECTIVA 2003/30/CE DO PARLAMENTO EUROPEU E DO CONSELHO (2003). Relativa à promoção da utilização de biocombustíveis ou de outros combustíveis renováveis nos transportes. Jornal Oficial da União Europeia. Disponível em: <http://eur-lex.europa.eu>. Acesso em: 25 de outubro de 2014.

DIRECTIVA 2009/28/CE DO PARLAMENTO EUROPEU E DO CONSELHO (2009) Diretiva relativa à promoção da utilização de energia proveniente de fontes renováveis que altera e subsequentemente revoga as Diretivas 2001/77/CE e 2003/30/CE. Jornal Oficial da União Europeia. Disponível em: <http://eur-lex.europa.eu>. Acesso em: 25 de outubro de 2014.

EUROPEAN STANDARD. EN 14111: Fatty acid methyl esters (FAME): determination of iodine value, 2003. 7p.

EN 14214: European Biodiesel Standard, 2005.

FIGUEIRA, S.R. Os programas de álcool como combustível nos EUA, no Japão e na União Europeia e as possibilidades de exportação do Brasil. Tese (Doutorado em Ciências, Área de Concentração: Economia Aplicada) - Escola Superior de Agricultura "Luiz de Queiroz", Piracicaba: USP. 2005.

FREITAS, E.; QUEIRÓS, M. As geopolíticas dos biocombustíveis e as novas correlações de forças entre Portugal, no contexto da União Europeia, e o Brasil. XII Colóquio internacional de geocritica. Universidade de Lisboa, Portugal. 2012. Disponível em: <http://www.ub.edu/geocrit/coloquio2012/actas/13-E-Freitas.pdf>. Acesso em: 11 de outubro de 2014.

GARCEZ, C.; VIANNA, J. Brazilian Biodiesel Policy: Social and Environmental Considerations of Sustainability. Energy. 34, 2009. p. 645-654.

GLENISTER, D.; NUNES, V. Entendendo a Produção Sustentável de Biocombustíveis, a Diretiva da UE de Energia Renovável e as Iniciativas Internacionais para Verificação de Sustentabilidade. Guia Técnico. Systems and Services Certification (SGS). 2011. Disponível em: <http://www.sgsgroup.com.br/pt-BR/Finance/Lenders-Adviser/Monitoring.aspx>. Acesso em: 15 de setembro de 2014.

JANK, M.S.; TACHINARDI, M.H. Prioridades agrícolas na Rodada de Doha em 2006: subsídios domésticos e acesso para produtos sensíveis. Revista Brasileira de Comércio Exterior, Rio de Janeiro, n. 86, p. 4-8, jan./mar. 2006.

LIMA, R.C. de A. Medidas sanitárias e fitossanitárias na OMC: neoprotecionismo ou defesa de objetivos legítimos. São Paulo: Aduaneiras, 2005.

MACHADO, A.P.C. A formulação da política comercial externa agrícola: condicionantes internacionais e domésticos da transformação institucional do Ministério da Agricultura, Pecuária e Abastecimento. Dissertação (Mestrado em Relações Internacionais) - Brasília: UNB. 2009.

MAISONNETT, L.H. As barreiras técnicas na organização mundial do comércio e a exportação de biocombustíveis: conflitos e contradições entre Brasil e União Europeia. Dissertação (Programa de Pós-Graduação em Direito) - Florianópolis: UFSC. 2011.

MALHÃO, V.L.F. O caso de Portugal na aplicação das políticas Europeias no domínio dos biocombustíveis. Universidade de Lisboa, Faculdade de Ciências. Dissertação (Mestrado em Ciências e Tecnologias do Ambiente) - Faculdade de Ciências. Lisboa: Universidade de Lisboa. 2009. Disponível em: <http://hdl.handle.net/10451/1483>. Acesso em: 17 de setembro de 2014.

Caminhos de Geografia Uberlândia $\quad$ v. 17, n. 58 Junho/2016 $\quad$ p. 103-116 Página 12


MAPA - Ministério da Agricultura, Pecuária e Abastecimento. Projeções do Agronegócio: Brasil 2014/2015 a 2024/2025. Brasília: Mapa/ACS, 2015. Disponível em:<http://www.agricultura.gov.br/arq_editor/PROJECOES_DO_AGRONEGOCIO_2025_WEB. pdf>. Acesso em: 10 de outubro de 2015.

MDIC - Ministério do Desenvolvimento Indústria e Comércio Exterior. O futuro da indústria: biodiesel. Coletânea de artigos / coordenadores José Rincon Ferreira, Carlos Manuel Pedroso Neves Cristo. - Brasília: MDIC-STI/IEL, 2006. 145 p.: il. - (Série Política Industrial, Tecnológica e de Comércio Exterior, 14). Disponível em: <http://www.desenvolvimento.gov.br//arquivos/dwnl_1201279825.pdf>. Acesso em: 25 de fevereiro de 2016.

MENDES, P.A.S. Priorização dos fatores determinantes da sustentabilidade da cadeia produtiva do biodiesel. Tese (Doutorado em Tecnologia de Processos Químicos e Bioquímicos) - Escola de Química. Rio de Janeiro: UFRJ. 2012. Disponível em: $<$ http://tpqb.eq.ufrj.br/download/sustentabilidade-da-cadeia-produtiva-do-biodiesel.pdf $>$. Acesso em: 22 de agosto de 2014.

MESQUITA, P.E. Multifuncionalidade e preocupações não comerciais: implicações para as negociações agrícolas na OMC. Brasília: FUNAG, 2005.

OCDE (2011). OECD-FAO. Agricultural Outlook 2011-2020. OECD Publishing and FAO. Disponível em: <http://www.oecd-ilibrary.org/agriculture-andfood/oecd-fao-agricultural-outlook2011_agr_outlook-2011 >>. Acesso em: 8 de maio de 2014.

MANCUSO, W.P.; OLIVEIRA, A.J. Abertura econômica e ação coletiva do empresariado no Brasil. Lua Nova: Revista de Cultura e Política, v. 69, p. 147-172, 2006.

OLIVEIRA, M.F. Multilateralismo, democracia e política externa no Brasil: contenciosos das patentes e do algodão na Organização Mundial do Comércio (OMC). Contexto Internacional, Rio de Janeiro, v. 29, n. 1, p. 7-38, 2007. Disponível em: $<$ http://www.scielo.br/scielo.php?script=sci_arttext\&pid=S0102-

$85292007000100001 \&$ Ing=en\&nrm=iso >. Acesso em: 17 de setembro de 2014.

PUTNAM, R. Diplomacy and Domestic Politics: the logic of two-level games. International Organization, Toronto, 1988. Vol. 42, n.3, p. 427-461.

Diplomacia e política doméstica: a lógica dos jogos de dois níveis. Revista de Sociologia Política. Curitiba, 2010. Vol. 18, n.36, p. 147-174.

SARAIVA, M. G. As estratégias de cooperação Sul-Sul nos marcos da política externa brasileira de 1993 a 2007. Revista Brasileira de Política Internacional. Brasília. vol. 50, n.2, p. 42-59, 2007.

U.S. DEPARTAMENT OF AGRICULTURE. Agricultural Projections to 2020. Washington: USDA, 2014.

ÚNICA - União da Indústria da Cana-de-açúcar Brasileira. Produção e uso do etanol combustível no Brasil. São Paulo, 2015. Disponível em: <http://www.unica.com.br>. Acesso em: 25 de março de 2015.

ZILLA, C.; RÖHRKASTEN, S. O comércio de biocombustível e conversas entre Brasil e UE. Economia, parlamentos, desenvolvimento e migrações: as novas dinâmicas bilaterais entre Brasil e Europa / [tradução Mónica Baña]. - Rio de Janeiro: Konrad-Adenauer-Stiftung, 2012. p. 85-104. 